\title{
PRÁTICAS INTERDISCIPLINARES NA FORMAÇÃO INICIAL DE PROFESSORES DE CIÊNCIAS DA NATUREZA: CONTEXTOS DISTINTOS, INDAGAÇÕES SIMILARES
}

\author{
João Henrique C. de Moura ${ }^{1}$ \\ https://orcid.org/0000-0002-0110-3226
}

\author{
- $\quad$ Maria Inês Petrucci Rosa²
}

$\bullet$

Elisa Prestes Massena ${ }^{3}$
https://orcid.org/0000-0002-7670-0201

\section{RESUMO:}

A ideia de interdisciplinaridade se estabeleceu no cenário educacional brasileiro nas últimas décadas, levando a demandas pela realização de atividades interdisciplinares no contexto escolar. Ao contrário do que preconizam os documentos curriculares, tais práticas não acontecem naturalmente. Ancorados em Goodson, argumentamos que as disciplinas escolares não apresentam fronteiras esmaecidas. Assim, investigamos como práticas interdisciplinares são engendradas na formação inicial de professores das Ciências da Natureza, no âmbito de estágios supervisionados em duas universidades públicas, uma no Sudeste, outra no Nordeste brasileiro. Analisamos relatórios e roteiros produzidos pelos licenciandos com a Análise Textual Discursiva. Apesar de indicarem possibilidades de se trabalhar interdisciplinarmente, nota-se que o estabelecimento de tais práticas não é trivial. $\mathrm{O}$ notável pertencimento à área de formação e a robustez da organização disciplinar dentro da escola sinalizam a importância das negociaçốes e do trabalho coletivo para o engendramento de práticas interdisciplinares.

\section{PRÁCTICAS INTERDISCIPLINARIAS EN LA FORMACIÓN INICIAL DE PROFESORES DE CIENCIAS NATURALES: DISTINTOS CONTEXTOS, PREGUNTAS SIMILARES}

\section{RESUMEN:}

La idea de interdisciplinariedad se ha asentado en el escenario educativo brasileño en las últimas décadas, generando demandas de actividades interdisciplinarias en el contexto escolar. $\mathrm{Al}$ contrario de lo que recomiendan los documentos curriculares, estas prácticas no ocurren de forma natural. Basados en Goodson, argumentamos que las materias escolares no tienen fronteras borrosas. Así, investigamos cómo las prácticas interdisciplinarias se engendran en la formación inicial de los profesores de Ciencias Naturales, en el ámbito de las pasantías supervisadas en dos universidades públicas, una en el sureste y otra en el noreste de Brasil. Analizamos informes y guiones elaborados por los estudiantes de grado con Análisis Textual Discursivo. Si bien indican posibilidades de trabajo interdisciplinario, se observa que el establecimiento de tales prácticas no es banal. La notable pertenencia al área de formación y la solidez de la organización disciplinaria dentro de la escuela señalan la importancia de las negociaciones y el trabajo colectivo para el desarrollo de prácticas interdisciplinarias.

\footnotetext{
1 Instituto Federal de São Paulo, Campus Registro, SP, Brasil.

2 Universidade Estadual de Campinas, Faculdade de Educação, Campinas, SP, Brasil.

3 Universidade Estadual de Santa Cruz, Departamento de Ciências Exatas e Tecnológicas, Ilhéus, BA, Brasil.
}

Palavra-chave: Interdisciplinaridade; Formação inicial; Disciplina escolar.

Palabras clave: Interdisciplinariedad; Formación inicial; Disciplina escolar. 


\section{INTERDISCIPLINARY PRACTICES IN THE INITIAL TRAINING OF TEACHERS OF NATURAL SCIENCES: DIFFERENT CONTEXTS, SIMILAR INQUIRIES}

\begin{abstract}
:
The idea of interdisciplinarity has established itself in the Brazilian educational scenario in recent decades, leading to demands for interdisciplinary activities in the school context. Contrary to what curriculum documents advocate, such practices do not happen naturally. Anchored in Goodson, we argue that school subjects have no dimmed boundaries. Thus, we investigate how interdisciplinary practices are engendered in the initial training of natural science teachers, within the scope of supervised internships in two Brazilian public universities, one in the northeast region, the other in the southeast. Through the Discursive Textual Analysis (DTA), we analyze reports and scripts produced by the undergraduates. Although they indicate possibilities for interdisciplinary work, it is noted that the establishment of such practices is not trivial. The remarkable belonging to the area and the robustness of the disciplinary structure within the school indicates the importance of negotiating and working together for carrying out interdisciplinary practices.
\end{abstract}

Keywords:

Interdisciplinariedad;

Formación inicial;

Disciplina escolar.

\section{INTRODUÇÃO}

Nas últimas décadas, o cenário curricular brasileiro tem se notabilizado, no que se refere à esfera documental, pela presença da ideia de interdisciplinaridade desde a publicação das Diretrizes Curriculares Nacionais para o Ensino Médio, no final dos anos 1990 (Diretrizes Curriculares Nacionais, 1998), até a recente promulgação da controversa reforma do Ensino Médio (Lei n. 13.415, 2017).

Esses documentos apresentam a proposta de organização das tradicionais disciplinas escolares em áreas de conhecimento, considerando suas afinidades epistemológicas. Ainda no que tange às políticas curriculares oficiais, o mais recente documento aprovado no Conselho Nacional de Educação relativo ao Ensino Médio preconiza a organização do trabalho pedagógico em áreas de conhecimento, suprimindo completamente a menção aos campos disciplinares (Resolução CNE/CP n. 4, 2018). Nesse sentido, a Base Nacional Comum Curricular (BNCC) para o Ensino Médio desenvolve uma proposição em que os conhecimentos escolares em Ciências da Natureza sejam relacionados e articulados, sem definir claramente as contribuiçôes específicas advindas das disciplinas Biologia, Física e Química.

Em decorrência deste cenário que perpassa as últimas décadas, surgem demandas pelo trabalho interdisciplinar no âmbito da atuação docente, levando a uma naturalização das práticas interdisciplinares como atividades corriqueiras (Bortolato, \& Iglesias, 2017; Feistel, \& Mestrelli, 2009; Goodson, \& Petrucci-Rosa, 2018; Lima, \& Ramos, 2017; Mozena, \& Ostermann, 2016).

Por outro lado, pode-se argumentar que as fronteiras disciplinares não são frágeis, à medida que uma disciplina escolar não se constitui apenas como um conjunto de conhecimentos a serem ensinados, mas traz em si as características de uma comunidade disciplinar (Abreu, 2012; Goodson, 1997). Outras pesquisas mostram que dificuldades e limitaçôes se impóem diante das demandas, advindas sobremaneira dos documentos curriculares, pelo trabalho interdisciplinar (Moura, 2014; Mozena, \& Ostermann, 2014; Petrucci-Rosa, 2018).

Nesse sentido, a realização de práticas interdisciplinares, na esfera da atuação docente, não se constitui como uma atividade trivial. Há uma complexidade em se trabalhar além dos limites de cada uma das disciplinas escolares, que podem ser compreendidas como territórios, de forma que juntas perfazem um currículo-loteamento, metáfora proposta por Petrucci-Rosa (2007), em que 
O currículo como loteamento estabilizou-se na escola básica onde a especialização - traço mais forte de sua fonte inspiradora: a ciência moderna - é o que prepondera. Nesse loteamento, a disputa dentro do "tempoespaço" da semana torna-se dinâmica, inventando 'vencedores' e 'perdedores', mais merecedores ou menos dignos de atenção, no processo de formação que a escola se propõe a fazer (Petrucci-Rosa, 2007, p. 55).

A disciplina escolar, no bojo dessas questôes, se configura como um locus, onde não apenas os saberes científicos de referência ocupam espaço. As características e demandas da comunidade de sujeitos que a compõe também se fazem presentes. Esses territórios concorrem entre si para garantir espaços e atender os anseios dos habitantes da terra-natal disciplinar (Petrucci-Rosa, 2007), cujos limites não se esmaecem facilmente. Defendemos, assim, que as práticas interdisciplinares não podem ser tratadas como processos simples, que seriam naturalmente desenvolvidas no trabalho docente, como se pode inferir da leitura dos documentos oficiais (Matriz de Referência, 2009; Orientações Curriculares Nacionais, 2006; Parâmetro Curriculares Nacionais, 1999; Resolução CNE/CEB 2, 2012).

Assim, argumentamos baseados nos estudos de Goodson (2018), que atribuem a estabilização de uma disciplina no currículo da escola básica à correspondente carreira universitária. Os professores das etapas finais da escolarização básica, portanto, carregam consigo as tradiçôes e cultura(s) de um campo do saber que permeiam o professor desde os primeiros anos de sua formação. Não se pode olvidar, portanto, que as disciplinas escolares carregam em si um forte simbolismo, que não se apagaria facilmente diante de interpelaçóes interdisciplinares. Logo, o exercício da docência acontece a partir de uma lente com os filtros da linguagem e da episteme da disciplina a qual é vinculado (Petrucci-Rosa, 2018).

Para constituir o objeto de estudo do presente trabalho, focar-se-á na formação inicial docente como um possível caminho para se pensar práticas interdisciplinares, considerando as potencialidades de espaços formativos como os estágios supervisionados, como mostram algumas pesquisas (Bortolato, \& Petrucci-Rosa, 2013; Cabral, \& Flôr, 2016; Massena, 2015; Moretti, \& Petrucci-Rosa, 2015; Paniago, Sarmento, Medeiros, \& Nunes, 2018).

Elege-se a formação inicial como foco de investigação, uma vez que, problematizadas e pensadas como possíveis desde os primeiros anos de contato profissional com a instituição escolar, as práticas interdisciplinares poderiam se tornar substanciais. Delineia-se assim o escopo dessa investigação no âmbito dos estágios supervisionados de licenciandos da área de Ciências da Natureza, considerando a inserção no ambiente escolar na perspectiva dos estágios supervisionados.

Para dialogar com nossa questão investigativa, constituiu-se o material empírico a partir de relatórios e roteiros referentes ao contexto de disciplinas de Estágio Supervisionado de duas universidades públicas brasileiras, em que os licenciandos são convidados a trabalhar conjuntamente com colegas de outras disciplinas. O caminho metodológico está pautado nos princípios da Análise Textual Discursiva (ATD), que orientará a análise das produções escritas dos estagiários (Moraes, Galiazzi, 2016).

\section{A IDEIA DE INTERDISCIPLINARIDADE: ALGUMAS CONSIDERAÇÕES}

Apesar de se poder relacionar o surgimento do tema às primeiras universidades do mundo ocidental, as questôes relativas ao conhecimento interdisciplinar notadamente emergiram ao longo do século XX, especialmente a partir da segunda metade. O desenvolvimento da Ciência e a consequente especialização do conhecimento parecem ter sido os principais fatores que levaram a estudos epistemológicos sobre as possibilidades de interface e integração entre as disciplinas (Mathurin, 2002). A compartimentalização de saberes ensejou críticas que se propagaram do universo acadêmico para o escolar.

Assim, a defesa pela adoção de práticas interdisciplinares no contexto escolar surge historicamente como resposta aos problemas e dificuldades elencados por sujeitos da educação sobre os processos de ensino-aprendizagem. Considerando como ponto de partida a década de 1970, Veiga-Neto denominou tal debate de Movimento Pedagógico pela Interdisciplinaridade (Veiga-Neto, 2010). 
Esse movimento, relativo ao cenário brasileiro, começa a se desenrolar na década de 1970 e se consolida nos anos posteriores, norteado pelos trabalhos de Hilton Japiassu e Ivani Fazenda (Veiga-Neto, 2010). No bojo desse movimento, pode-se salientar as perspectivas teóricas acerca da interdisciplinaridade desses autores. Dentre as diversas contribuiçốes deles, pode-se destacar, respectivamente, questôes sobre a compartimentalização dos saberes e uma compreensão integral do mundo, bem como a percepção de que a interdisciplinaridade se daria por meio de mudanças atitudinais (Fazenda, 1994; Japiassu, 1976).

Importante destacar que, além das considerações epistemológicas sobre as dinâmicas do conhecimento no mundo contemporâneo, Japiassu, baseado principalmente em estudiosos franceses, trouxe proposiçóes para se entender o que seria $o$ interdisciplinar. Conjugado a outros três termos - multidisciplinar, pluridisciplinar e transdisciplinar -, esse autor tece os significados de cada um deles a partir do nível de interação entre as disciplinas.

Essa forma de interação entre as disciplinas pode ser entendida como uma gradação que se inicia no multidisciplinar, entendido como apenas uma aproximação das disciplinas, sem que haja um diálogo entre os conteúdos das mesmas. Em seguida, viria o pluridisciplinar, em que se poderia considerar um grau de relação entre as disciplinas, mas sem uma efetiva integração de seus saberes. Logo, o interdisciplinar corresponderia a uma efetiva interação entre conhecimentos, que contribuiria para o aprimoramento das disciplinas. Por fim, o transdisciplinar seria caracterizado como um nível elevado de integração, que poderia se constituir de relaçôes entre supostas interdisciplinas constituídas no nível anterior (Japiassu, 1976; Veiga-Neto, 2010)

No campo do ensino de Ciências, há um espectro de investigaçôes e reflexóes acerca das possibilidades da interdisciplinaridade. Podemos mencionar o artigo de Mozena e Ostermann (2014) e o trabalho de Lamego e Santos (2017), que estudaram a produção bibliográfica sobre interdisciplinaridade. O primeiro focou a análise em periódicos nacionais e internacionais concernentes à Educação, Qualis A1 e A2, com um recorte temporal entre 1980 e 2012. O último se dedicou a examinar os Anais do Encontro Nacional de Pesquisa em Ensino de Ciências (ENPEC) em suas dez primeiras ediçóes, compreendendo os anos de 1997 a 2015.

A análise desenvolvida por Mozena e Ostermann (2014) se baseou na revisão de 112 trabalhos em que a defesa pela interdisciplinaridade no ensino de ciências está presente. As autoras também destacam que muitos destes trabalhos apresentam e discutem ideias e temas para atividades interdisciplinares nas disciplinas das Ciências da Natureza. Elas ainda sintetizam que as principais dificuldades para o desenvolvimento da interdisciplinaridade podem ser agrupadas em quatro eixos, a saber: institucional, metodológico, relativo aos professores e relativo aos alunos. Lamego e Santos (2017), ao revisarem 85 publicaçóes de um conjunto de dez anais dos Encontros Nacionais de Pesquisa em Ensino de Ciências (ENPEC), salientam que os autores mais citados nesses trabalhos foram Hilton Japiassu e Ivani Fazenda, além de serem frequentes a defesa pela interdisciplinaridade e discussóes acerca de questóes teóricas sobre os termos multidisciplinar, pluridisciplinar, interdisciplinar e transdisciplinar. Ambos os estudos evidenciam que os autores mais citados nos trabalhos revisados, além dos brasileiros já mencionados, foram Edgar Morin, Jurjo Santomé e Yves Lenoir.

Há também pesquisas que evidenciam a estabilidade das disciplinas e das comunidades escolares nas práticas curriculares da escola básica brasileira (Abreu, 2010; Petrucci-Rosa, \& Ramos, 2015; Petrucci-Rosa, 2018, Entre Outros). Tais investigaçóes evidenciam que o trabalho interdisciplinar, no contexto escolar, assume ampla dimensão, além da epistemológica e atitudinal.

Ainda nos reportando a Veiga-Neto (2010), parece haver duas grandes “ondas” de interdisciplinaridade na recente história educacional brasileira, a saber: a primeira delas, de natureza acadêmica, se constitui na circulação de trabalhos de Japiassu e Fazenda; a segunda, de natureza política, é marcada pela aprovação de um conjunto de documentos curriculares. Assim, a partir dos documentos curriculares do final dos anos de 1990, o tema interdisciplinaridade entra em voga no campo da Educação e do Ensino de Ciências, e passa a circular narrativamente nas políticas públicas curriculares brasileiras nas primeiras duas décadas dos anos 2000 .

Considerando-se as interpelações advindas dos documentos curriculares oficiais sobre a interdisciplinaridade, parece haver uma certa naturalização sobre o trabalho interdisciplinar, muitas vezes considerado 
uma responsabilidade exclusiva dos docentes. É esse ponto que nos move na trajetória da presente investigação, à medida que reconhecemos que a ideia de interdisciplinaridade não se configura uma panaceia curricular, mas, ao contrário, demanda estudos e compreensão na dimensão da formação de professores.

Nesse sentido, considerando o contexto da escola básica, mormente o Ensino Médio, nota-se uma significativa influência da cultura dos campos disciplinares (Goodson, \& Rosa, 2018; Petrucci-Rosa, 2007) na formação inicial dos professores e nas dinâmicas do cotidiano escolar e do trabalho docente. Ao se abordar o tema interdisciplinaridade no contexto de atuação docente, fazemo-lo dentro de uma perspectiva disciplinar, considerando que

Ser professor(a) de uma determinada disciplina escolar é uma condição que vai além da dimensão epistemo-

lógica ou cognitiva - é carregar também consigo as práticas advindas do campo simbólico configurado nas relaçóes de poder presentes na sua comunidade acadêmica de referência (Petrucci-Rosa, 2007, p. 58).

Os campos disciplinares, assim, salientam sua importância nas organizações curriculares, justificando a força e perenidade no contexto escolar. Os docentes de cada disciplina, principalmente aqueles dos anos finais do Ensino Fundamental e do Ensino Médio constituem, portanto, comunidades disciplinares (Goodson, 2018). Nesse sentido, reiteramos que as práticas interdisciplinares não se configuram como algo natural no trabalho docente. Os professores das etapas finais da escolarização básica são professores de uma disciplina. Em outras palavras, é possível afirmar que a disciplina assume uma espécie de "sobrenome" do professor: a professora "Alzira” é de Química, professor “Abelardo” é de Física ...

Como aponta Goodson, as tradições e culturas dos campos disciplinares são elementos garantidores da manutenção do status e espaço curricular de uma disciplina escolar (Goodson, 2001, 2007, 2019). Com essas consideraçôes, assumimos que as condiçôes de desenvolvimento de práticas interdisciplinares não dependem apenas de uma mudança de atitude e paradigma epistemológico, mas sim da complexa teia de relações culturais e pedagógicas que são tecidas na escola. As práticas interdisciplinares se estabelecem, portanto, no bojo do trabalho coletivo como questão pedagógica (Petrucci-Rosa, 2018).

Sendo assim, o presente trabalho tem como objetivo discutir a complexidade das práticas interdisciplinares na formação inicial de professores, partindo do contexto de experiências em disciplinas de estágio supervisionado ocorridas entre os anos de 2013 e 2017 de duas universidades públicas brasileiras: uma localizada na regiáo Sudeste e outra no Nordeste.

\section{CAMINHOS METODOLÓGICOS}

O material empírico da presente investigação é constituído por produçôes textuais de licenciandos oriundas das atividades produzidas durante o período em que realizaram o estágio supervisionado. Nas duas instituições, há cursos de licenciaturas referentes a todas as disciplinas presentes na organização curricular da escola básica. A universidade do Sudeste se organiza em diversos institutos e faculdades que carregam os respectivos nomes das disciplinas que representam. A universidade do Nordeste, por sua vez, se organiza em departamentos por áreas de conhecimento. Descrevemos a seguir características comuns aos estágios realizados nas duas instituições. Após, detalhamos os contextos de desenvolvimento desses estágios nas universidades do Sudeste e do Nordeste.

Em ambas as universidades, as experiências dos professores em formação se configuraram a partir dos encontros semanais das disciplinas relacionadas ao estágio supervisionado. Como proposta inicial, os estudantes são convidados a realizar um conjunto de leituras sobre a imersão no universo escolar. Na interação com os orientadores e supervisores do estágio, docentes responsáveis pelas disciplinas e professores da escola básica, respectivamente, os licenciandos constroem um caminho de regência e atuação no campo de estágio.

No âmbito desse trabalho, destacamos dois conjuntos de experiências de estágios, um de cada universidade, envolvendo licenciandos de disciplinas das Ciências da Natureza. Em comum, todas elas elaboraram projetos e aulas para serem trabalhados no contexto escolar. As práticas advindas dessas atividades apresen- 
tam como semelhança a construção de atividades interdisciplinares planejadas no escopo de cursos de formação inicial de professores e foram desenvolvidas em escolas públicas.

Em relação à universidade do Sudeste, trazemos três experiências que envolveram licenciandos de Química e Biologia na interação com colegas das Ciências Humanas, Matemática e Linguagens, devido à própria natureza do estágio naquela instituição, detalhada a seguir. No caso da universidade do Nordeste, a vivência de estágio aconteceu no contato entre licenciandos de Química e Física, acompanhados por duas estudantes de mestrado da mesma universidade, ligadas ao programa de pós-graduação em educação em Ciências e Matemática. Uma delas tem formação em Biologia e a outra em Química. Todas essas situaçóes ocorreram sob a orientação da docente responsável pela disciplina de estágio na respectiva universidade. Estas informações estão sumarizadas no Quadro 1.

A experiência de estágio na universidade da Região Sudeste do Brasil está centrada em dois pilares. Um deles se assenta no contexto específico da disciplina em que o licenciando graduar-se-á e é desenvolvido pelo respectivo instituto/faculdade. O outro é de responsabilidade da Faculdade de Educação e comum a todas as licenciaturas. Nesse caso, a proposta de realização dos estágios não reside nas disciplinas em si, mas na compreensão das complexidades do espaço escolar e da atividade docente. As diferentes turmas da disciplina de estágio supervisionado se organizam em projetos, nos quais os licenciandos podem se matricular considerando suas afinidades com o tema. Desta maneira, estudantes de diferentes licenciaturas podem compartilhar as vivências de estágio. Assim, a carga horária total dos estágios é compartilhada, de forma que os estudantes vivenciem momentos próprios do seu campo disciplinar e discussões mais amplas sobre os espaços educativos.

O desenrolar dessas experiências e vivências, no caso da universidade do Sudeste, culminou na produção de relatórios. Os licenciandos matriculados na disciplina de estágio se organizam em grupos com três/quatro membros, geralmente de cursos diferentes. Cada grupo escolhe um tema que contemple as disciplinas envolvidas e elaboram uma proposta interdisciplinar para desenvolverem juntos em uma escola pública. Ao final do processo, o grupo escreve coletivamente um único relatório, no qual é narrado todo o processo de imersão na escola, observação de aulas e desenvolvimento do projeto interdisciplinar. Nesses documentos, há trechos com os relatos identificados de cada licenciando e as análises, impressôes e reflexôes conjuntas dos estagiários. Os relatórios foram elaborados em três oferecimentos distintos de uma das disciplinas de estágio, abrangendo o período de 2013 a 2017. Eles serão denominados pela sigla $R$, seguida dos dois algarismos finais do ano de sua produção.

$\mathrm{Na}$ universidade da Região do Nordeste brasileiro, os estágios supervisionados se desenvolvem sob responsabilidade dos departamentos onde os cursos de licenciatura estão sediados. Em cada um deles, há docentes da área de ensino que ministram as respectivas disciplinas e desenvolvem os projetos de estágio em conjunto com escolas da rede pública. As horas de estágio que devem ser cumpridas são relacionadas a quatro ou três disciplinas, a depender do curso. A primeira metade do estágio é destinada à aproximação e observação do campo escolar, enquanto a regência ocorre na outra metade.

Assim, no contexto da universidade do Nordeste, os licenciandos produziram roteiros de aulas com cunho interdisciplinar, dentre os quais são elencados três. Os temas destas atividades encontram-se no Quadro 2 na próxima seção. Os roteiros, que apresentam sequências de desenvolvimento das etapas das aulas propostas, foram desenvolvidos em 2017. Eles serão identificados pelas siglas Ro1, Ro2 e Ro3, conforme consta no Quadro 1. Os roteiros Ro1, Ro2 e Ro3 foram organizados para atividades a serem realizadas em até cinco encontros de $1 \mathrm{~h}$ e 15 minutos. As turmas eram compostas por estudantes do 1o e 2 o anos do Ensino Médio. As atividades foram construídas nos momentos de Atividade Complementar (AC) que ocorrem uma vez por semana, durante 2 horas, nas escolas da rede pública estadual com a participação de professores da escola, da universidade, licenciandos e mestrandos, sujeitos oriundos das áreas de Biologia, Física, Química e Matemática. As atividades em sala de aula eram realizadas por um professor da escola e um licenciando.

$\mathrm{Na}$ análise do material empírico, os licenciandos envolvidos são representados pela letra " $\mathrm{L}$ ", acompanhada também pela letra inicial do curso. Um licenciando de Biologia, por exemplo, é referido como LB. 
Cabe mencionar que excertos específicos de falas dos estudantes dos cursos das outras áreas que compóem os relatórios não constituem objeto de análise, considerando a temática do presente artigo.

\begin{tabular}{|l|l|l|l|}
\hline Região & Tipo de material & Código & Disciplinas envolvidas \\
\hline \multirow{3}{*}{ Sudeste } & Relatório - 2013 & R13 & Sociologia, Biologia e Química \\
\cline { 2 - 4 } & Relatório - 2014 & R14 & Biologia, Filosofia e Química \\
\cline { 2 - 4 } & Relatório - 2017 & R17 & Biologia, Língua Portuguesa, Matemática e Química \\
\hline \multirow{3}{*}{ Nordeste } & Roteiro 1 - 2017 & Ro1 & Física, Matemática e Química \\
\cline { 2 - 5 } & Roteiro 2 - 2017 & Ro2 & Biologia, Física, Matemática e Química \\
\cline { 2 - 4 } & Roteiro 3 - 2017 & Ro3 & Biologia, Física, Matemática e Química \\
\hline
\end{tabular}

Figura 1. Material empírico analisado.

Fonte: Elaborado pelos autores, 2020.

A análise dos relatórios e roteiros que compóem nosso material empírico é engendrada pela perspectiva de uma pesquisa qualitativa (Bodgan, \& Bicklen, 1994; Minayo, 2012). Como dispositivo metodológico, consideramos os princípios da Análise Textual Discursiva (ATD) desenvolvida por Moraes e Galiazzi (2016), que consiste em quatro etapas, a saber: a) a desmontagem dos textos; b) estabelecimento de relaçóes; c) captação do novo emergente e d) um processo organizado. Em outros termos:

Organizada em quatro focos, a Análise Textual Discursiva visa, inicialmente, à desmontagem dos textos, seu exame nos mínimos detalhes. Na sequência, desenvolve-se o estabelecimento de relaçóes entre cada unidade, procurando-se a identidade entre elas, para, logo após, captar o que emerge da totalidade do texto, em direção a uma nova compreensão desse todo. Por fim, o processo de pesquisa, nesta metodologia de análise, é auto-organizado, exigindo do pesquisador uma imersão, a completa impregnação nas informações do texto analisado, sendo esta rigorosidade uma necessidade para que o novo tenha condiçóes de ficar evidente (Pedruzzi, Schimdt, Galiazi, \& Podewils, 2015, p. 591-592).

Assim, todo o material empírico foi lido e o corpus analisado compreendeu, portanto, os textos dos relatórios e dos roteiros. O processo de desmontagem dos textos se inicia pela leitura minuciosa desses materiais à procura de enunciados referentes aos aspectos a serem discutidos, tais como a interdisciplinaridade e a formação docente. $\mathrm{O}$ estabelecimento de relaçôes se dá pela própria categorização, reunindo elementos próximos encontrados nos textos. A captação do novo emergente está associada à leitura e impregnação dos materiais a serem analisados. Há, desta forma, uma nova compreensão do todo, e nessa etapa constitui-se a escrita do metatexto para, por fim, possibilitar a emergência de novas compreensóes do todo com o ciclo de análise. Assim, tem-se um processo auto-organizado (Moraes, \& Galiazi, 2016).

Considerando-se as quatro etapas mencionadas anteriormente e imbuídos da leitura do material empírico, chegamos à definição de três categorias emergentes, quais sejam: a) a casa disciplinar; b) o enfrentamento do ambiente escolar e c) o abandono da terra-natal. Sobre elas, discorreremos a seguir.

\section{O CAMPO EMPÍRICO E SUA ANÁLISE}

Os dados serão discutidos a partir das categorias definidas anteriormente em articulação com a abordagem metodológica assumida neste trabalho.

a) A casa disciplinar - "proteção dos conteúdos"

Em geral, a formação de professores nos cursos de licenciatura ocorre de forma disciplinar, com os 
licenciandos sendo formados em campos específicos que momentaneamente podem dialogar entre si. Considerando esse aspecto, quando chegam às disciplinas de 'ensino de' e são confrontados a articularem distintos campos disciplinares, percebem dificuldades importantes, uma vez que pensar e a agir dessa forma exige uma renúncia à proteção e à segurança que os conteúdos disciplinares proporcionam. Ao serem interpelados em trabalhar interdisciplinarmente, os licenciandos precisam adentrar a "casa do outro" ao mesmo tempo em que as portas de suas próprias casas ficam abertas. Naturalmente, eles recorrem às suas áreas de origem quando da execução dos projetos disciplinares no contexto do estágio supervisionado, e é notável a fluência com que os licenciandos discorrem sobre o seu próprio campo disciplinar.

Por exemplo, no R14 em que estão envolvidos licenciandos de Biologia, Filosofia e Química, eles decidem elaborar uma proposta de atividade interdisciplinar a partir da temática do método científico. No entanto, durante a execução da atividade, eles trabalharam isoladamente, a partir de saberes próprios de suas disciplinas. Como argumentamos alhures, a disciplina escolar não é um ente isolado que reproduz conhecimentos da correspondente disciplina científica, mas integra uma complexa teia que é a comunidade disciplinar (Goodson, 2001, Abreu, 2012). Cada docente é professor de uma disciplina, o que reforça o pertencimento a um lugar específico, a uma casa disciplinar, a uma terra-natal. Nas palavras do licenciando em Biologia:

Como segundo momento da aula, eu, representando a Biologia, me apresentei aos alunos, e continuei a explicar o que é método científico. Em seguida, eu quis materializar a ideia de método científico com um exemplo prático - uma historinha. Eu contei para eles a história de um jovem garoto que adorava biologia e queria descobrir alguma coisa, queria ser um pesquisador. Para isso, ele sabia que devia começar observando um fato da natureza, já que biologia é uma ciência natural (R14, LB).

Este estagiário reforça a identificação com a disciplina de origem ao se anunciar como representante da Biologia, e a coloca como central para se compreender o método científico. Em conjunto, os três licenciandos propuseram uma intervenção através de um procedimento experimental sobre a fotossíntese, que representaria uma interface interdisciplinar entre a Química e a Biologia, além de possibilitar uma discussão sobre a construção do conhecimento. Percebemos, através dos relatos deles, que a lógica disciplinar dos conteúdos prepondera, conforme destacamos no excerto a seguir.

Através de colisões entre as moléculas dos reagentes da fotossíntese (água e gás carbônico), as ligações químicas destes são quebradas e novas ligações são formadas nos produtos desta reação (glicose, oxigênio e água).

Terminei, assim, a parte teórico-científica de química (R14, LQ).

Os professores em formação inicial propõem discussões acerca do método científico, cada qual dentro do seu campo disciplinar, como salienta o licenciando em Química ao dizer que terminou "a parte teórico-científica de química”. Não há indícios no relatório de que trabalharam efetivamente juntos, articulando os diferentes saberes.

Os estagiários parecem discorrer com fluência no contexto de seu próprio campo disciplinar, evidenciando inclusive uma preocupação com o rigor dos conteúdos a serem ensinados. Em outra experiência de estágio, representada pelo relatório R13, em que participaram licenciandos de Biologia, Química e Sociologia, que decidiram trabalhar com o tema "Plantas medicinais", a licencianda em Biologia expressa suas angústias com a impossibilidade de ter realizado uma abordagem mais detalhada dos conteúdos de sua disciplina:

Como estávamos em roda e de maneira até bastante informal, senti uma dificuldade grande em medir o que falaria e em qual nível de aprofundamento. Um dos motivos que me gerou essa angústia foi que havíamos deixado no cronograma uma parte da aula seguinte para uma discussão química e biológica mais aprofundada. No entanto, no momento da discussão surgiu a oportunidade de tratar já assuntos como etnobotânica e metabólitos secundários. Não consegui entrar em detalhes e não achava que deveria, mas a forma como acabei falando me deixou com a sensação que não abordei da forma e nem do aprofundamento certo e, como a princípio havia um espaço mais específico para esses assuntos, principalmente a parte dos metabóli- 
tos, que é muito interessante, pois abre espaço para uma discussão relacionada com evolução, acabei falando que abordaríamos mais detalhadamente no dia seguinte (R13, LB).

A preocupação com os conhecimentos específicos das disciplinas é presente em todos os roteiros e relatórios elaborados pelos licenciandos. Os representantes de cada terra-natal advogam a favor de seus campos ao discorrerem com riqueza de detalhes sobre os conteúdos de suas "casas disciplinares". O professor iniciante de Química que compõe a equipe do R13, ao contar suas impressóes sobre as aulas que assistiu, salienta imprecisões na explicação da professora regente. Paradoxalmente, ao mesmo tempo em que ele tece críticas, reconhece as limitações do contexto das aulas do Ensino Médio, sem abandonar, entretanto, a defesa pela correta observância dos princípios químicos. Referindo-se à influência da temperatura em reações químicas, ele diz:

Embora eu também tenha aprendido dessa forma no ensino médio, na universidade vi que o aumento da temperatura favorece (no sentido de aumentar a velocidade) todas as reações, sejam elas endotérmicas ou exotérmicas, e que, no caso de equilíbrio químico, o aumento da temperatura favorece mais a reação endotérmica do que a reação exotérmica (R13, LQ).

Ainda, após mencionar a equação de Arrhenius, que traz um aparato matemático - função exponencial e logaritmo - relativamente complexo aos conteúdos de nível médio, ele reconhece:

Entendo que esse nível de detalhamento talvez não se encaixe em uma aula de ensino médio, mas fiquei um pouco incomodado em ver os alunos aprendendo algo da mesma forma que eu aprendi quando estava na posição deles, de uma maneira apenas parcialmente correta (R13, LQ).

A despeito das consideraçôes sobre as diferenças entre conhecimento escolar e científico e sobre o conceito de transposição didática que podem ser tecidas a partir do excerto anterior, o incômodo sentido pelo licenciando em Química com a inobservância do rigor científico e dos conteúdos de seu campo disciplinar sinaliza a fortaleza que a "casa disciplinar" representa. Para que práticas interdisciplinares sejam efetivas, são necessárias negociações e concessões por parte dos envolvidos. Conforme argumenta Petrucci-Rosa (2007), o espaço-tempo escolar, com "seus perdedores e vencedores", com mais ou menos horas-aula, é uma teia de relaçôes complexas com diferentes ritos e sujeitos ocupando lugares. Um trabalho interdisciplinar implica abandonar certas certezas e idiossincrasias e carregar outras. A integração de saberes de diferentes disciplinas demanda um constante "apego" e "desapego" aos conteúdos.

Os conhecimentos específicos se revelam ora como muros, ora como alicerces das distintas casas disciplinares, a despeito das propostas interdisciplinares construídas pelos estagiários. No caso dos componentes do grupo que elaborou o relatório R17, cujo tema abordado foi depressão e ansiedade, os licenciandos de Biologia e Química foram bem minuciosos na descrição dos conteúdos que eles mobilizaram. Em relação aos saberes da Biologia, a licencianda trouxe muitos detalhes sobre o funcionamento do sistema nervoso e endócrino, bem como tratou da neurofisiologia relacionada à depressão. Em relação aos conhecimentos químicos, há muitas informaçôes específicas sobre compostos orgânicos. Da mesma forma, os roteiros estão centrados nos momentos das aulas reservados para a discussão dos conteúdos disciplinares.

Além das notáveis preocupações dos estagiários em trabalhar devidamente os princípios epistemológicos de cada disciplina, o que parece nortear as diferentes práticas, os estudantes precisam lidar com um complexo universo constituído pelo cotidiano escolar, que também exerce influência sobre as condiçóes para que práticas interdisciplinares possam ocorrer.

b) O enfrentamento do ambiente escolar

Quando os licenciandos se deparam com a vivência no ambiente escolar, muitas preocupações e receios vem à tona. Primeiramente, essa vivência passará por um descolamento da figura de ser estudante, uma vez que o licenciando passa a exercer o papel de professor, assumindo o enfrentamento de questóes práticas da rotina de sala de aula e, dentre elas, a organização do espaço e do tempo. 
Tal assunção pode mobilizar um conjunto de crenças, sentimentos e emoções contraditórios, que em certa medida produz efeitos sobre as práticas pedagógicas dos docentes iniciantes.

Tivemos grandes dificuldades com o planejamento das aulas. E não porque não conseguíamos unir as disciplinas sob um mesmo tema ou por ser difícil conciliar os horários. As dificuldades foram exteriores ao nosso grupo, mais especificamente provenientes da disponibilidade de tempo que a escola cedeu para desenvolvermos o projeto na escola (R13).

Assim, parece que uma das principais características da dinâmica escolar que causa estranhamento é a organização do espaço-tempo da escola. Petrucci-Rosa (2007, p. 54-55), ao propor a metáfora de um currículo loteamento ao se referir a grade de horários das disciplinas escolares, argumenta que "a disputa dentro do 'tempoespaço' da semana torna-se dinâmica, inventando 'vencedores' e 'perdedores', mais merecedores ou menos dignos de atenção”. Dessa maneira, para se pensar diferentes atividades fora do escopo disciplinar, os licenciandos acabam por negociar o precioso recurso que é o tempo de aula. Nas palavras deles:

Desenvolver tal projeto permitiu a percepção de como a organização do tempo é de extrema importância e como, muitas vezes, é difícil conciliar este fator com o planejamento pré-estabelecido pela escola ou pelos próprios professores, já que diferentes professores possuem diferentes rotinas e compromissos (R17).

Ademais, outras questões emergem nos relatos dos estagiários, como o acesso aos projetos pedagógicos, comportamentos, posturas e expectativas dos adolescentes quanto ao processo de ensino-aprendizagem e a presença deles nas aulas. Em relação a este último:

Fui apresentada aos alunos e eles pareciam comemorar o recebimento de um doce. Bateram palmas, assobiaram, gritaram, foi uma cena bastante engraçada. A professora me explicou depois que eles adoram estagiários porque nossa presença lá implica que, em algum momento, eles farão algo diferente da dinâmica cotidiana da sala de aula (R14, LB).

Dos excertos destacados, podemos salientar que há uma certa rigidez na organização do ambiente escolar. A presença de uma terceira figura no espaço da sala de aula é suficiente para causar euforia nos estudantes. O formato tradicional das aulas, com um único professor, muitas vezes isolado, ocupando um tempo bem delimitado, constitui uma normalidade instituída no cotidiano da escola. Como indicam os outros fragmentos, o tempo escolar é uma barreira a ser superada para que as práticas interdisciplinares possam se fazer presentes. Os licenciandos precisam, ainda, que os professores supervisores cedam suas respectivas aulas para a viabilidade da intervenção interdisciplinar. A licencianda em Biologia, no R13, relata a dificuldade enfrentada pelo grupo perante o "modus operandi" escolar.

A negociação para conseguirmos as aulas para desenvolver o projeto não foi fácil. Tivemos então que fazer uma "edição" do que tínhamos inicialmente planejado. O que, em minha opinião, foi ao mesmo tempo muito difícil e decepcionante, porque o tema que escolhemos (Plantas Medicinais) envolve diretamente as três áreas de conhecimento envolvidas (Química, Biologia e Sociologia), e dá abertura para fazer uma gama de coisas (LB, R13).

Nesse sentido, nos parece crível dizer que o estabelecimento de práticas interdisciplinares não está circunscrito apenas ao universo dos conteúdos das disciplinas escolares e da disposição dos licenciandos em construir diálogos. Para além das possibilidades de integração dos conhecimentos, a dinâmica da escola é um fator importante para o êxito de tais práticas. Seria importante pensarmos em termos de espaços interdisciplinares, de modo que a interação entre docentes ocupando e dividindo o mesmo espaço e tempo seja facilitada pela estrutura escolar.

Como relatou a licencianda em Biologia, do R14, a presença dela representou um rompimento, ainda que sutil, da normalidade instituída do território disciplinar, que tem como símbolo o professor especialista, que detém a posse do intervalo temporal que se denomina "aula”. Assim, questionamos se é plausível considerar que práticas interdisciplinares podem se estabelecer com cada sujeito isoladamente abordando conteúdos sobre um tema. 
O enfrentamento do ambiente escolar, portanto, é também um enfrentamento da "solidão" do território disciplinar. A aula, como unidade basilar da distribuição do tempo escolar, é sempre associada a um campo do saber nos anos finais da escola básica. Essa segmentação naturalmente se faz presente no planejamento das atividades interdisciplinares propostas.

Os licenciandos do R17, p. ex., se referem ao projeto elaborado como "A depressão segundo a química, biologia, matemática e a língua portuguesa”, salientando as contribuiçóes de cada disciplina para o entendimento do tema. No relatório, eles trazem minúcias sobre os conteúdos de suas disciplinas e quase não há a preocupação de dividirem o mesmo espaço. Apenas em uma das etapas previstas por eles nota-se a coexistência de assuntos de língua portuguesa e matemática: "Apresentação de diversos gêneros não literários e dados estatísticos”.

O abandono da "casa disciplinar" não se configura como uma tarefa simples e o próprio ambiente escolar, com suas culturas e tradições instituídas, que se constitui como o lugar onde o abandono da terra-natal pode acontecer, onde se pode ensaiar o rompimento de padróes, impóe muitos desafios para a negociação em prol das práticas interdisciplinares.

c) O abandono da "terra-natal” - os temas como possibilidade de ampliação de conhecimentos produzidos

Como as atividades deveriam apresentar propostas de intervenções interdisciplinares, é interessante compreender como os temas foram escolhidos, os quais estão sumarizados na figura 2 a seguir.

\begin{tabular}{|l|l|l|}
\hline Código & Tema & Disciplinas envolvidas \\
\hline R13 & Plantas Medicinais & Sociologia, Biologia e Química \\
\hline R14 & Teorização e construção do conhecimento científico & Biologia, Filosofia e Química \\
\hline R17 & Depressão e Ansiedade & Biologia, Língua Portuguesa, Matemática e Química \\
\hline Ro1 & Energia dos alimentos & Física, Matemática e Química \\
\hline Ro2 & Drogas lícitas - medicamentos & Biologia, Física, Matemática e Química \\
\hline Ro3 & Drogas ilícitas & Biologia, Física, Matemática e Química \\
\hline
\end{tabular}

Figura 2. Os temas trabalhados nas atividades interdisciplinares.

Fonte: Elaborado pelos autores, 2020.

Nos relatórios produzidos no contexto das atividades vivenciadas no Sudeste, o que se observa é que a escolha do tema partiu de questionamentos sobre a relevância do tema e da facilidade de integração das diferentes disciplinas. No caso de R13:

O tema para o projeto interdisciplinar surgiu pensando mais na diversidade das disciplinas de licenciatura dos membros do grupo do que de algo que possivelmente teria emergido na escola. Inicialmente, pensamos em trabalhar algum assunto relacionado à questão ambiental, mas a mãe de um dos membros do grupo sugeriu o tema das Plantas Medicinais e adotamos a sugestão, já que o uso de plantas tradicionais faz parte do cotidiano de muitas famílias (...)

Cabe o questionamento: ao se apropriar do conhecimento das plantas medicinais, a ciência reestrutura as relaçóes e distribuição de conhecimento na sociedade? (R13)

Já no caso do R14, a ideia foi, a partir do tema “Teorização e construção do conhecimento científico" e de uma experiência sobre Fotossíntese, discutir como os componentes curriculares auxiliam na construção do conhecimento. O R17 menciona a discussão do tema "Depressão e Ansiedade" como de relevância para os jovens da escola. Cabe salientar que este processo de decisão não é simples e exige diálogo entre os representantes das disciplinas, bem como um sólido conhecimento acerca do seu campo. Nos dizeres dos licenciandos:

A etapa de criação do projeto interdisciplinar nos mostrou como ainda são necessários estudos para enten- 
der a interdisciplinaridade de fato e então poder aplicá-la nas salas de aula. Além de nos mostrar, através da dificuldade de comunicação devido a termos específicos de cada área, por exemplo, que estamos mais enraizados na nossa formação do que percebemos (R17).

Por outro lado, os temas dos roteiros (Ro1, Ro2 e Ro3) elaborados no contexto da experiência vivenciada no Nordeste foram definidos a partir de uma conversa com professores da escola em que foi mencionada a importância de se discutir uma alimentação mais saudável e o consumo de drogas lícitas e ilícitas pelos estudantes. Os roteiros apresentam em suas atividades a problematização inicial do tema, com apresentação de algumas questões para o debate, o uso de vídeos, experimentos simples, discussão de bulas, leitura de textos curtos e júri químico.

Parece evidente que a discussão a partir de temas pode ser uma estratégia importante para se exercitar o abandono da terra-natal (Petrucci-Rosa, 2007) dos conteúdos disciplinares, partindo para um exercício da articulação de distintos campos de conhecimento.

\section{DIALOGANDO COM AS EXPERIÊNCIAS INTERDISCIPLINARES NO ÂMBITO DA FORMAÇÃO INICIAL DOCENTE}

A despeito das dificuldades relatadas pelos licenciandos, é fundamental destacar o reconhecimento do esforço realizado por cada grupo no processo de definição de um tema em que fosse possível a articulação dos conhecimentos disciplinares. A intensa relação que os estudantes demonstram com os conteúdos da área de formação parece ser um indicativo de como as práticas essencialmente disciplinares, que valorizam o saber especializado, perduram. Os futuros professores são confrontados a pensar práticas interdisciplinares, formas de integração de conhecimentos, no momento que se encontram imersos no contexto do estágio supervisionado.

Consideramos, assim, a complexidade dos processos de formação docente nas licenciaturas relativos às práticas interdisciplinares, com especial atenção aos espaços curriculares configurados pelos estágios supervisionados. Nas licenciaturas, raramente são encontrados outros espaços curriculares onde conhecimentos interdisciplinares são abordados ou construídos. De uma maneira geral, as licenciaturas disciplinares são calcadas em currículos marcados por conhecimentos próprios de cada área científica, com especial ênfase nas especializações.

Nesses cursos, o espaço curricular representado pelos estágios supervisionados configura-se como importante lugar de ressignificação acerca da importância dos conhecimentos e suas possibilidades de didatização para sua transformação em conhecimento escolar. Isso pode explicar a percepção da importância da "casa disciplinar" como aspecto identitário docente que ocupa centralidade nas práticas pedagógicas planejadas e desenvolvidas no contexto das escolas. A fala da licencianda em Biologia, do R14, quando diz "eu representando a Biologia”, é uma notável expressão desse aspecto identitário e mostra que o abandono da terra-natal não acontece totalmente.

Tal constatação nos remete ao que Goodson (2019, p. 65) aponta, citando Kliebard, que afirma: "a fortaleza que se revelou praticamente inexpugnável era a disciplina escolar”. Kliebard se refere a um estudo de perspectiva histórica desenvolvido sobre o currículo americano no período entre 1893 e 1958 . No entanto, essa fortaleza parece ainda permanecer evidente nas práticas curriculares que se propõem interdisciplinares, desenvolvidas em contextos diversos da formação inicial. No Ro1, p. ex., há uma ênfase nos conteúdos específicos de Física e Química, assim como nos Ro2 e Ro3 são valorizadas as estruturas químicas. Da mesma forma, os licenciados no R14 se baseiam no processo da fotossíntese para o diálogo interdisciplinar entre Biologia e Química. Após proporem uma atividade experimental, os licenciandos dessas disciplinas privilegiam a discussão de conhecimentos especializados de suas áreas, em detrimento das contribuiçóes de cada disciplina para a compreensão global da fotossíntese.

A valorização do conhecimento do próprio campo disciplinar se destaca na configuração das práticas interdisciplinares, o que constitui uma forma de garantia da estabilização disciplinar, conforme argumenta Goodson (2018). Segundo esse autor, esse caráter de fortaleza disciplinar se dá principalmente pela mobilização 
de conhecimentos escolares de tradição acadêmica. Nesse sentido, nos relatórios e nos roteiros, percebemos a preocupação de se mencionar e mobilizar conhecimentos acadêmicos de cada campo disciplinar específico. $\mathrm{O}$ licenciando em Química, no R14, enaltece as definiçôes de “teoria das colisôes” e "energia de ativação", tratando mais de aspectos gerais de uma reação química, do que as transformações ocorridas na fotossíntese em si.

A partir dessas consideraçóes, pautar nos estágios curriculares a possibilidade de se produzir conhecimento escolar de natureza interdisciplinar acaba por se configurar quase como uma transgressão que exige especial esforço e abertura para o trabalho coletivo docente. Além do movimento de deslocamento da terra-natal disciplinar, o êxito dessas práticas interdisciplinares na formação inicial desses professores também depende da superação das amarras institucionais estabelecidas na escola. Como contaram os licenciandos, a conquista do tempo de aula dos professores supervisores demandou muito esforço e negociação. Sem o envolvimento com a dimensão coletiva por parte dos estagiários, professores e escola, torna-se mais complexo ainda o planejamento de práticas interdisciplinares.

Como afirma Goodson (2019, p. 172), "É nas arenas institucionais mais amplas que os professores percebem tanto as grandes frustrações quanto as possibilidades de mudanças significativas”. Pensar as práticas interdisciplinares no estágio supervisionado, com suas devidas complexidades e potencialidades de ressignificação do conhecimento disciplinar e a efetiva parceria da escola e de todos seus entes, pode se configurar em uma forma menos solitária de enfrentamento do ambiente escolar. Além de possibilitar uma rica experiência institucional envolvendo formadores - professores universitários - e os professores experientes que recebem os licenciandos no campo de trabalho.

Como afirmado em Petrucci-Rosa (2018), a experiência interdisciplinar se estabelece principalmente a partir de duas dimensóes: o trabalho coletivo e a questão pedagógica. Nos relatórios e roteiros produzidos nas experiências de estágio supervisionado das duas universidades, tais dimensóes se evidenciam à medida que percebemos a importância das parcerias que podem ser estabelecidas entre licenciandos e atores da escola no processo de escolhas e tomadas de decisão sobre os processos de ensino propostos. Considerar esses princípios nos processos formativos docentes vai na contramão do que preconizam documentos curriculares que assumem a interdisciplinaridade como prática pedagógica trivial e facilmente instituída no contexto da escola (Goodson, \& Rosa, 2018).

Os licenciandos do R17, quando afirmam "a etapa de criação do projeto interdisciplinar nos mostrou como ainda são necessários estudos para entender a interdisciplinaridade de fato”, nos sinalizam essa complexidade que se configura inerente ao trabalho disciplinar, uma vez que não se pode olvidar as dimensões coletivas e pedagógicas, conforme afirma Petrucci-Rosa (2018).

Práticas interdisciplinares podem ser assumidas como eixos formativos constitutivos da formação docente nas licenciaturas, desde que seja ponderada toda a profunda complexidade envolvida para além das interaçôes entre as disciplinas, o que demanda que preceitos de trabalho coletivo sejam prioritariamente valorizados.

\section{REFERÊNCIAS}

Abreu, R. G. A produção cultural da comunidade disciplinar de Ensino de Química. Periferia - Educação, Cultura छ Comunicą̧ão. v. 4, n. 1, jan-jul, 2012

Bogdan, R. C., Biklen, S. K. Investigação qualitativa em educação: uma introdução à teoria e aos métodos. Porto: Porto Editora, 1994.

Bortolato, C. A., IGLESIAS, J. O. V. Interdisciplinaridade no Ensino Médio com a mediação do cinema. In: PetrucciRosa, M. I., Rampini, E. A. (orgs). Práticas Curriculares e Narrativas Docentes em diferentes contextos. Curitiba, Editora CRV, p. 211-228, 2017.

Cabral, W. A., Flôr, C. C. C. (Re)pensando as práticas de escrita na disciplina de estágio supervisionado em química: 
com a palavra, os estagiários. Ens. Pesqui. Educ. Ciênc. (Belo Horizonte) v.18, n.3, Sept./Dec, 2016. Disponível em $<$ http://dx.doi.org/10.1590/1983-21172016180308>. Acesso em: 25 jun. 2020

Feistel, R. A. B., Maestrelli, S. R. P. Interdisciplinaridade na formação de professores de Ciências Naturais e Matemática: algumas reflexôes. In: VII Encontro Nacional de Pesquisa em Educação em Ciências. Florianópolis. Atas do VII ENPEC, 2009.

Goodson, I. F. A construção social do currículo. Tradução de Maria João Carvalho. Lisboa: Educa, 111p, 1997. (Coleção Educa-Currículo).

Goodson, I. F. Curriculo, Narrativa Pessoal e Futuro Social. Campinas: Editora da Unicamp, trad: Henrique Carvalho Calado, 2019.

Goodson, I. F. Currículo: Teoria e História. 15a. ed. Petrópolis: Editora Vozes, 2018.

Goodson, I. F. Para além do monólito disciplinar - Tradiçôes e subculturas. In: Goodson, I. F. O Currículo em Mudança - Estudos na construção social do currículo. Tradução de Jorge Ávila de Lima. Portugal: Porto, 2001. p. 173194. (Coleção Currículo, Políticas e Práticas).

Goodson, I. F., ROSA, M. I. F. P. The Journey of School Knowledge and the concept of refraction. Pro-posiçôes, v. 29, n. 1 (86), jan./abr., p. 296-320, 2018. Disponível em <https://doi.org/10.1590/1980-6248-2016-0052>. Acesso em: 25 jun. 2020

Lamego, C. R. S., Santos, M. C. F. Interdisciplinaridade e educação em ciências: uma pesquisa bibliográfica nos Anais do I - X ENPEC (1997 - 2015). In: XI Encontro Nacional de Pesquisa em Educação em Ciências. Florianópolis. Atas do XI ENPEC, 2017. Disponível em <http://www.abrapecnet.org.br/enpec/xi-enpec/anais/resumos/R1317-1.pdf>. Acesso em: 25 jun. 2020

Lei n. 13.415, de 16 de fevereiro de 2017 (2017). Institui a Reforma do Ensino Médio. Diário Oficial da União. Brasília, DF. Disponível em: <http://www.planalto.gov.br/ccivil_03/_ato2015-2018/2017/lei/113415.htm>. Acesso em: 10 jun. 2020.

Lima, V. M. R., Ramos, M. G. Percepçôes de interdisciplinaridade de professores de Ciências e Matemática: Um Exercício de Análise Textual Discursiva. Revista Lusófona de Educação, v. 36, p.163-177, 2017. Disponível em <https:// revistas.ulusofona.pt/index.php/rleducacao/article/view/5997>. Acesso em: 25 jun. 2020

Massena, E. P. A formação inicial de professores de química pensada a partir de alguns pressupostos do educar pela pesquisa. Educacao Unisinos (Online), v. 19, p. 45-56, 2015. Doi: 10.4013/edu.2015.191.04. Acesso em: 25 jun. 2020

Mathurin, C. Aspects de L'interdiscplinarité: Essai de Reconstitution d'um Débat. In: L'interdisciplinarité et la recherche sociale appliquée Réflexions sur des expériences en cours. Editépar Lucie Gélineau. Université de Montréal. p. 7 - 39. 2002. Disponível em <http://www.etudes-sup.fas.umontreal.ca/sha/documents/interdisciplinarite.pdf $>$. Acesso em: 25 Jun. 2020.

MEC (1999). Parâmetros Curriculares Nacionaispara o Ensino Médio. Brasília: Secretaria de Educação Médiae Tecnológica.

MEC (2006). Orientaçôes Curriculares Nacionais para o Ensino Médio. Brasília: Secretaria da Educação e Tecnologia.

MEC (2009). Matriz de Referência para o Novo Enem. Brasília: Instituto Nacional de Estudos e Pesquisas Educacionais Anísio Teixeira.

Minayo, M. C. S. (Org.), Deslandes, S. F., Gomes, R. Pesquisa social: teoria, método e criatividade. 31 ed. Petrópolos, RJ: Vozes, 2012.

Moraes, R., Galiazzi, M. C. Análise textual discursiva. 3 ed. rev. e ampl. 2017. Ijuí: Ed. Unijuí, 2016, 264p.

Moretti, R. C. B., Petrucci-Rosa, M. I. Interdisciplinaridade no Ensino Médio: Narrativas docentes a respeito do Projeto PIBID Ciências da Natureza. In: Anais X Encontro Nacional de Pesquisa em Educação em Ciência - X ENPEC. Águas de Lindoia, 2015. Disponível em <http://www.abrapecnet.org.br/enpec/x-enpec/anais2015/resumos/R04061.pdf $>$. Acesso em: 25 jun 2020

Moura, João Henrique. A Integração Curricular no Enem: o caso das Ciências da Natureza. Campinas: Unicamp, 2014, 130 f. Dissertação (Mestrado em Educação) - Faculdade de Educação, Universidade Estadual de Campinas, Campinas, 2014. Disponível em <http://repositorio.unicamp.br/jspui/handle/REPOSIP/254172>. Acesso em: 25 jun. 2020 
Mozena, E. R., Ostermann, F. A interdisciplinaridade na legislação educacional, no discurso acadêmico e na prática escolar do Ensino Médio: panaceia ou falácia educacional?. Caderno Brasileiro de Ensino de Física, v. 33, n. 1, p. 92-110, abr-2016.

Mozena, E. R., Ostermann, F. Uma Revisão Bibliográfica sobre a interdisciplinaridade nas ciências da natureza. Ensaio, v.16, n. 02, p. 185-206, maio-ago, 2014. Disponível em <http://dx.doi.org/10.1590/1983-21172014160210>. Acesso em: 25 jun. 2020

Paniago, R. N., Sarmento, T. J., Medeiros, J., Nunes, P. G. Um cenário de possibilidades para o estágio curricular supervisionado no contexto de um Instituto Federal. Ensaio, v.20, e11044, Epub Oct 04, 2018. Disponível em <https:// doi.org/10.1590/1983-211720182001022>. Acesso em: 25 jun. 2020

Pedruzzi, A. N., Schimdt, E. B., Galiazi, M. C., Podewils, T. M. Análise Textual Discursiva: os movimentos da metodologia de pesquisa. Atos de Pesquisa em Educação. Blumenau, v. 10, n.2, p.584-604, mai./ago. 2015. Disponível em <http://dx.doi.org/10.7867/1809-0354.2015v10n2p584-604>. Acesso em: 25 jun. 2020

Petrucci-Rosa, M. I. Currículo de Ensino Médio e Conbecimento Escolar: das políticas às histórias de vida. Curitiba: Editora CRV, 154p, 2018.

Petrucci-Rosa, M. I. Experiências Interdisciplinares e formação de professore(a)s de disciplinas escolares: imagens de um currículo-diáspora. Revista Pro-Posiçôes, v.18, n.2, p. 51-65, 2007.

Petrucci-Rosa, M. I., Bortolato, C. A. Interdisciplinaridade: uma experiência no estágio curricular das licenciaturas na relação com artefatos culturais.Olh@res, Guarulhos, v. 1, n1, p. 401-415, maio, 2013.

Resolução CNE/CEB n. 2, de 31 de janeiro de 2012 (2012). Define Diretrizes Curriculares Nacionais para o Ensino Médio. Diário Oficial da União. Brasília, DF: Ministério da Educação, Conselho Nacional de Educação.

Resolução CNE/CP n. 4, de 17 de dezembro de 2018 (2018). Institui a Base Nacional Comum Curricular na etapa do Ensino Médio. Diário Oficial da União. Brasília, DF: Ministério da Educação. Conselho Nacional de Educação. Conselho Pleno. Disponível em <>http://portal.mec.gov.br/docman/dezembro-2018-pdf/104101-rcp004-18/file. Acesso em: 25 jun. 2020

Santomé, J. T. Globalização e Interdisciplinaridade: o currículo integrado. Porto Alegre: Artmed, 1998.

Veiga-Neto, A. Tensões disciplinares e Ensino Médio. In: I Seminário Nacional: Currículo em Movimento - Perspectivas Atuais. Belo Horizonte. Atas do I Seminário Nacional: Currículo em Movimento - Perspectivas Atuais, 2010. Disponível em: <http://portal.mec.gov.br/docman/dezembro-2010-pdf/7178-4-3-tensoes-disciplinares-ensinomedio-alfredo-veiga/ file>. Acesso em: 25 jun. 2020.

\section{João Henrique C. de Moura}

Doutor em Ensino de Ciências e Matemática, Instituto Federal de São Paulo, campus Registro, membro GepCE e GPCEM - Grupo de Pesquisa em Ciências Naturais, Educação e Matemática.

E-mail: joaofq3@gmail.com

\section{Maria Inês Petrucci Rosa}

Doutora em Educação, professora Livre-Docente da Faculdade de Educação, Universidade Estadual de Campinas, Campinas, SP, membro do GepCE - Grupo de estudo e pesquisa em ciência e ensino e coordenadora do GePraNa - Grupo de estudos em práticas curriculares e narrativas docentes. E-mail: minespetrucci@gmail.com

\section{Elisa Prestes Massena}

Doutora em Educação, Docente na área de Ensino de Química, Departamento de Ciências Exatas e Tecnológicas, Universidade Estadual de Santa Cruz, Ihéus, BA; Grupo de Pesquisa em Currículo e formação de professores em ensino de ciências - GPeCFEC,

E-mail: elisapmassena@gmail.com

Contato: 
Maria Inês Petrucci Rosa

Universidade Estadual de Campinas | Faculdade de Educação. Avenida Bertrand Russell, n. 308 | Cidade Universitária Campinas, SP | Brasil CEP 13.083-970

Editor responsável: Paulo Henrique Dias 